\title{
DESIGNING A SHAPED SEAT-PAN CUSHION TO IMPROVE POSTURAL (DIS)COMFORT REDUCING PRESSURE DISTRIBUTION AND INCREASING CONTACT AREA AT THE INTERFACE
}

\author{
Fiorillo, Iolanda (1); \\ Song, Yu \{Wolf\} (2); \\ Vink, Peter (2); \\ Naddeo, Alessandro (1) \\ 1: University of Salerno; \\ 2: Delft University of Technology
}

\begin{abstract}
Remaining seated for extended periods increases the risk health issues and discomfort perception. Consequently, the seat-pan design is crucial and could be mainly influenced by two factors: pressure distribution and seat contour. For seat pan discomfort, the lower average pressure is accompanied by less discomfort. Moreover, a seat contour with a large contact area is correlated with more comfort. Thus, a shaped cushion had been accurately designed (Virtual Prototype) and realized (Physical Prototype) aiming to translate the pressure distribution due to interaction between seat and buttock in a geometric shape, suitable for the international population (including P5 females and P95 males). With this shape, the pressure should be more uniform and lower, the contact area at interface bigger, and the perceived comfort higher. Both Virtual and Physical Prototype design had been described in this paper through a repeatable and straightforward approach. Also, experiments had been performed to validate the hypothesis through a comparison with a standard flat cushion. Results showed the goal of the design had been reached: the shaped cushion scored less pressure distribution and higher contact area than the flat cushion.
\end{abstract}

Keywords: Product modelling / models, User centred design, Design methodology, Surface modelling, Prototype manufacturing method

\author{
Contact: \\ Fiorillo, Iolanda \\ University of Salerno \\ Industrial Engineering \\ Italy \\ ifiorillo@unisa.it
}

Cite this article: Fiorillo, I., Song, Y., Vink, P., Naddeo, A. (2021) 'Designing a Shaped Seat-Pan Cushion to Improve Postural (Dis)comfort Reducing Pressure Distribution and Increasing Contact Area at the Interface', in Proceedings of the International Conference on Engineering Design (ICED21), Gothenburg, Sweden, 16-20 August 2021. DOI:10.1017/ pds.2021.111 


\section{INTRODUCTION}

Designing a comfortable seat is of great importance but is complicated (Hiemstra-van Mastrigt, Meyenborg, et al., 2016; Kamp, 2012; Vink, 2016). Several factors concerning the interaction between human and seat (Vink, 2016) should be considered early in the design process, such as anthropometric measurements (Molenbroek et al., 2017), body shape (Hiemstra-van Mastrigt, Groenesteijn, et al., 2016), body sensitivity (Vink and Lips, 2017), postures (Groenesteijn et al., 2014), and perceived comfort (El Falou et al., 2003; Kyung and Nussbaum, 2008; Mansfield et al., 2015; Naddeo et al., 2019; Naddeo and Memoli, 2009; Zenk et al., 2006).

Since there are many factors involved in seat design, realizing a prototype early in the design process is beneficial, especially to reduce the Time To Market (Gibson et al., 2004). The purpose of building a prototype (i.e. prototyping) is usually to embody design hypotheses, test the function and feel of the new design and elicit market feedback prior to production of a product (Liu, 2011). Nowadays, the new product development process makes use of both virtual and physical prototypes. Virtual Prototyping (VP) and Physical Prototyping (PP) are two techniques that have many similar goals, but which achieve them in very different ways. With VP, the approach is to create a precise numerical model, which can be manufactured in a simple way, whereas in PP a physical model is created (Gibson et al., 2004; Liu, 2011). Sometimes, virtual prototyping needs support from physical prototyping in some product evaluations, such as product ergonomics, due to the natural sensation of human perceptions (Anderl et al., 2007).

Assessing seat comfort and discomfort is a topic widely discussed in the literature (Helander and Zhang, 1997; Kolich and Taboun, 2004; Zhang et al., 1996), and seat manufacturers appear to still rely strongly on subjective evaluations as the main indicator of seat comfort and discomfort (Cascioli et al., 2016).

The main goal is to design a comfortable and suitable seat for any considered population preventing health issues and creating well-being. For instance, remaining seated for extended periods increases the risk of pressure ulcers in the buttocks area, as the soft tissue in this area is squeezed between two surfaces: the seat and the bones of the pelvis (A consensus document, 2010; Krouskop et al., 1983; Schubert et al., 1994; Stephens and Bartley, 2017). Moreover, the blood flow is significantly decreased when sitting 3 hours without moving the body (McManus et al., 2015; Thosar et al., 2014).

One way to solve this problem could be the adoption of a massage system to stimulate blood circulation (Franz et al., 2008). Another way could be improving seat design. In particular, the seat pan design could be mainly influenced by two factors: pressure distribution and seat contour (Kamp, 2012).

When people sit, the relevant contact areas are on the backrest and the seat-pan. The interface pressure on the seat-pan varies over the area of the seat surface because the human buttocks are not flat. This local variation in pressure on the seat surface, namely the "pressure distribution", is affected by several factors, such as the seat hardness, seat shape and anatomical characteristics of the passenger's buttocks.

Furthermore, the pressure distribution on the seat pan influences the discomfort in the lower back (Zenk et al., 2006). A physiological link exists as well: too much pressure on the buttocks in addition to the muscle tension to erect the pelvis can be perceived as pain in the lower back (Zenk et al., 2006). The concept of "optimal load distribution" (Zenk et al., 2012) might be helpful and occurs between human and seat in finding the most comfortable posture, and there are indications that the pressure in the intervertebral disc is lowest in the optimal position (Franz et al., 2010).

The pressure distribution is the objective measure with the most evident association with subjective ratings of discomfort compared to other measures (De Looze et al., 2003). Also, to assess the perceived (dis)comfort objectively, the pressure mapping system is the most widely used thanks to its relatively low cost and easy use (Wang et al., 2020; Zemp et al., 2015), and presents statistical correlations with discomfort (Hiemstra-van Mastrigt, Groenesteijn, et al., 2016; De Looze et al., 2003). Moreover, interface pressure depends on postures, seat characteristics (also the shape), assumed body positions, anthropometric measurements (Hiemstra-van Mastrigt, Groenesteijn, et al., 2016, Naddeo et al., 2018).

Moreover, there are indications that a seat contour resulting in a larger contact area is correlated to more comfort (Fang et al., 2016; Zemp et al., 2016; Zenk et al., 2012). One way to achieve this would be to use soft foam in the cushion, which follows the contour of the user's buttocks. Another way 
would be to use a shaped contour shell derived from the human body and useless foam. Ideally, this suits to a large population from P5 females to P95 males ("DINED", n.d.).

Smulders (Smulders et al., 2016) developed a human contour shaped seat shell using a 3D scanner and adapted the cushion form to improve comfort, reduce weight and optimize the space. The prototype seat had significantly lower average pressures between subjects' buttocks and the seat pan compared with a traditional seat.

Since literature studies showed a low-pressure distribution and a human contour shaped seat could lead to more comfort, this work aims to combine these two important factors. Based on pressure mapping, a shaped seat pan has been developed using 3D software (virtual prototype) and manufactured as a physical prototype. A comparison with a standard flat seat pan has been made to verify this hypothesis. The research question is: has the designed-shaped seat-pan reached the goal of better pressure distribution and larger contact area than a standard flat seat-pan?

\section{MATERIALS \& METHOD}

\subsection{Basic idea}

The basic idea for the shaped cushion (for the seat-pan) was to follow the human body contour at the buttock-thigh area. With this shape, the contact area could theoretically be higher and, with the same body weight, the pressure at the interface could be lower and more uniform than that of the flat cushion (see Figure 1). Consequently, with less pressure, the perceived comfort might be higher, and postural discomfort lower. Furthermore, the shape should be suitable for the range from P5 female to P95 male of the international population ("DINED”, n.d.).

\subsection{Pressure acquisition}

The Pressure mat Xsensor LX210:48.48.02 (Table 1) was used to evaluate the pressure distribution. Its capacitive sensors are ideal for assessing automotive and aerospace seat design. The LX210 series of sensors are accurate due to high repeatability, low hysteresis, and low creep characteristics, and they have been used in a variety of research and product testing environments.

Table 1: Technical characteristics of pressure mat

\begin{tabular}{|c|c|c|}
\hline \multicolumn{3}{|c|}{ Physical characteristics } \\
\hline Total area & $32 "$ x 32" & $81.3 \mathrm{~cm} \mathrm{x} 81.3 \mathrm{~cm}$ \\
\hline Sensing Area & $24 " \times 24 "$ & $60.9 \mathrm{~cm} \mathrm{x} 60.9 \mathrm{~cm}$ \\
\hline Thickness (sensing area, uncompressed) & $0.03 "$ & $0.09 \mathrm{~cm}$ \\
\hline Thickness (border-cabling side) & $0.05 "$ & $0.11 \mathrm{~cm}$ \\
\hline \multicolumn{2}{|c|}{ Sensors } & $48 \times 48=2304$ \\
\hline Sensors number & $12.6875 \mathrm{~mm}$ \\
\hline sensor length & $160.9727 \mathrm{~mm} 2$ \\
\hline sensor area (square) & $370881 \mathrm{~mm} 2$ \\
\hline
\end{tabular}

The pressure mat gave as output .CSV files in which it was possible to obtain following data for each participant:

- Mean, max and min values of pressure distribution

- Map of average pressures on time

- Pressure variation overtime

- Contact areas overtime

- Definition the body shapes and their variation overtime

- Position of the buttocks on the seat pan according for each posture

\subsection{Data acquisition}

Experiments involved 22 participants (10 females and 12 males, Table 2) that were asked to sit on a standard seat assuming three different postures (sitting upright, slouched and bending forward) for 30 seconds. Reliability of the experiment has been respected with participants seated for all experiment duration (Hartung et al., 2004). 
Table 2: Anthropometric measurements of a previous experiment

\begin{tabular}{|c|c|c|c|c|c|c|}
\hline & Age & Weight $(\mathrm{kg})$ & Stature $(\mathrm{cm})$ & BMI & $\begin{array}{c}\text { Buttock } \\
\text { Knee } \\
\text { length } \\
(\mathrm{cm})\end{array}$ & $\begin{array}{c}\text { Hip Width } \\
(\mathrm{cm})\end{array}$ \\
\hline Mean & 24.18 & 71.55 & 175.64 & 23.00 & 61.32 & 36.57 \\
\hline $\begin{array}{c}\text { Standard } \\
\text { Deviation }\end{array}$ & 2.23 & 14.22 & 9.96 & 3.03 & 5.13 & 2.33 \\
\hline Range & $21-31$ & $48-96$ & $155-193$ & $17-29$ & $51.50-76$ & $29.70-41$ \\
\hline
\end{tabular}

Pressures (with Pressure mat Xsensor LX210:48.48.02) have been recorded after 10 second sitting (assessing time) and for 20 seconds (recording time), obtaining a data set of 39 frames for each second (780 acquisition for each participant). Then, these data have been merged to obtain an average pressure distribution, as shown in Figure 1.

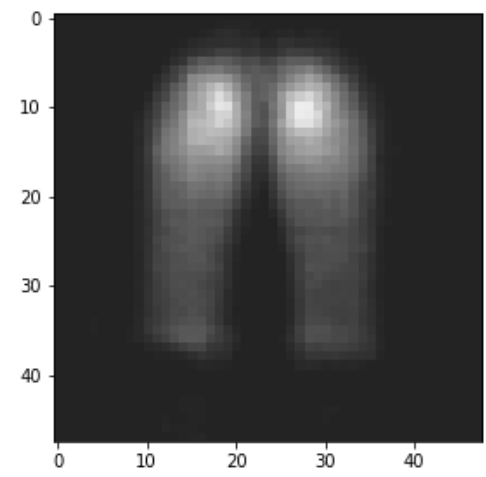

Figure 1: Result of average pressure distribution data acquisition

\subsection{D model}

Once calculated the average pressure map, the shape/contour has been realized using as third dimension the value of pressure:

- $\mathrm{X}$ - and $\mathrm{Y}$-axis: The $\mathrm{X}$ and $\mathrm{Y}$ dimension of the pressure map (length and width of the shape obtained with pressure distribution)

- Z-axis: local pressure values (deepness of the shape)

The pressure profile has been mapped to " $0-1$ " domain within the Grasshopper to obtain a modelled surface. Grasshopper is a visual programming language and environment that runs within the Rhinoceros 3D computer-aided design (CAD) application. Then the domain has been customized to a new domain "0-maximal depth".

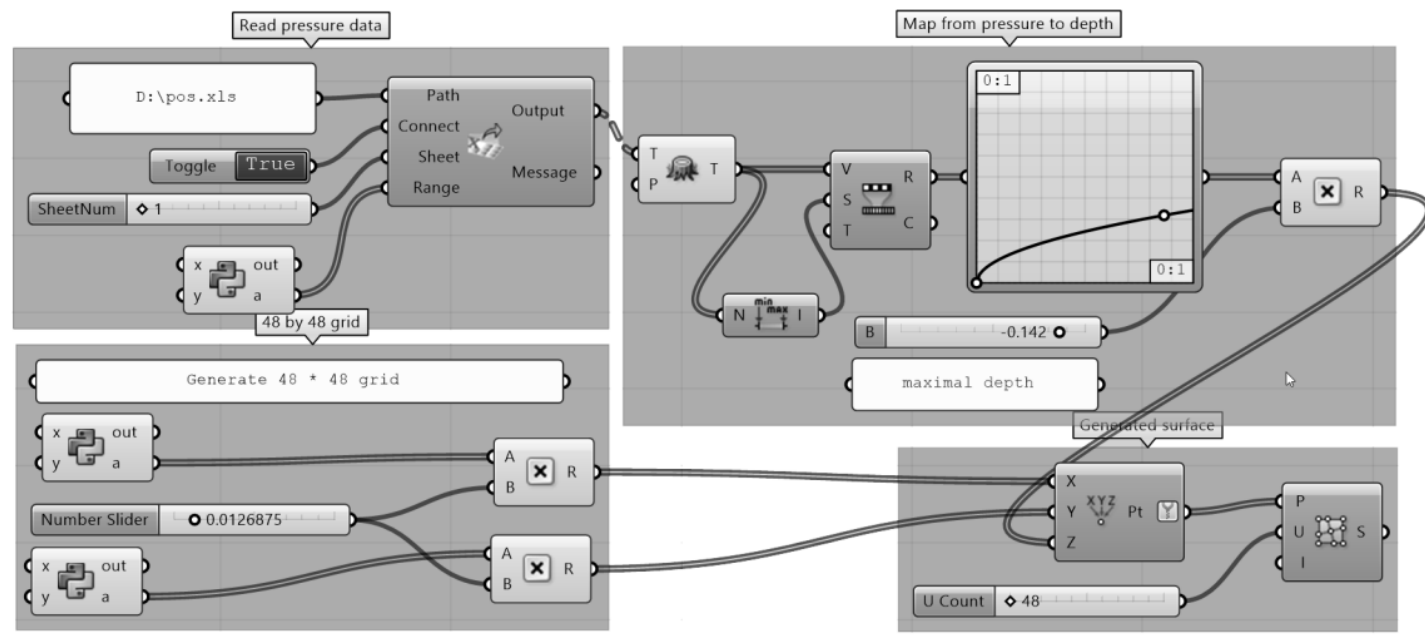

Figure 2: Grasshopper scheme used. Pressure distribution data as input, converted into $3 D$ domain and obtaining as output the 3D surface. 
Once the values were set as shown in Figure 2, which the profile has been displayed in Rhinoceros environment, the surface has been baked (Figure 3) and exported into IGES format. The file was a NURBS surface that can be easily edited in any CAD software or directly in Rhino.

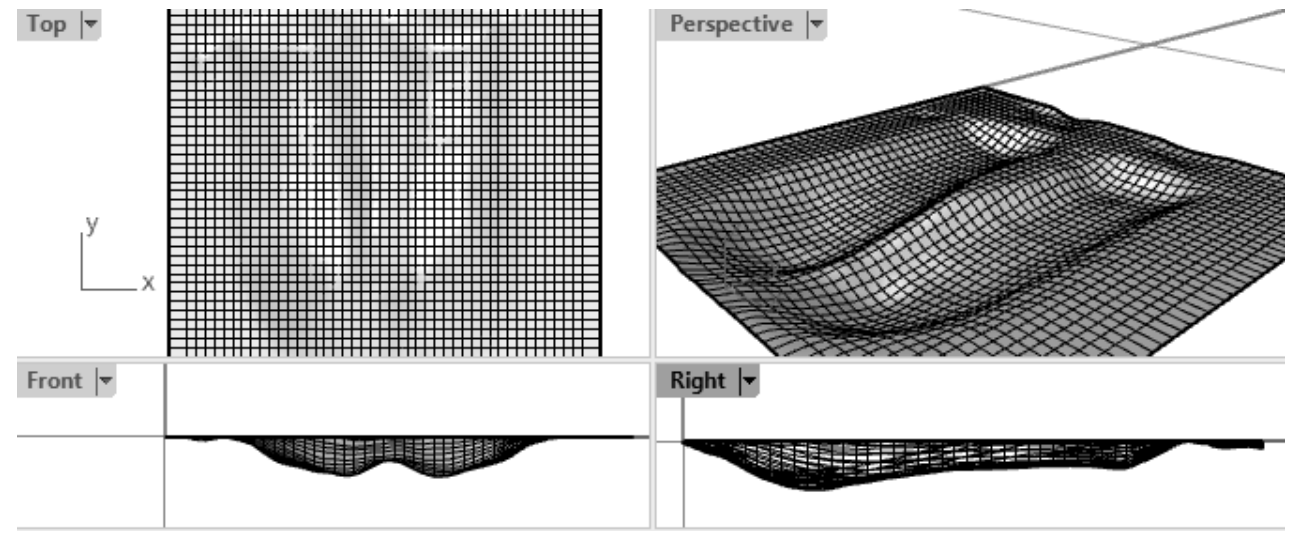

Figure 3: 3D surface obtained from Grasshopper

For the easiness of construct a solid model based on surface, the software Solidworks ${ }^{\circledR}$ has been used to design the set pan. Figure 4 presents the imported surface, the 3D CAD design and the dimensions of the model.

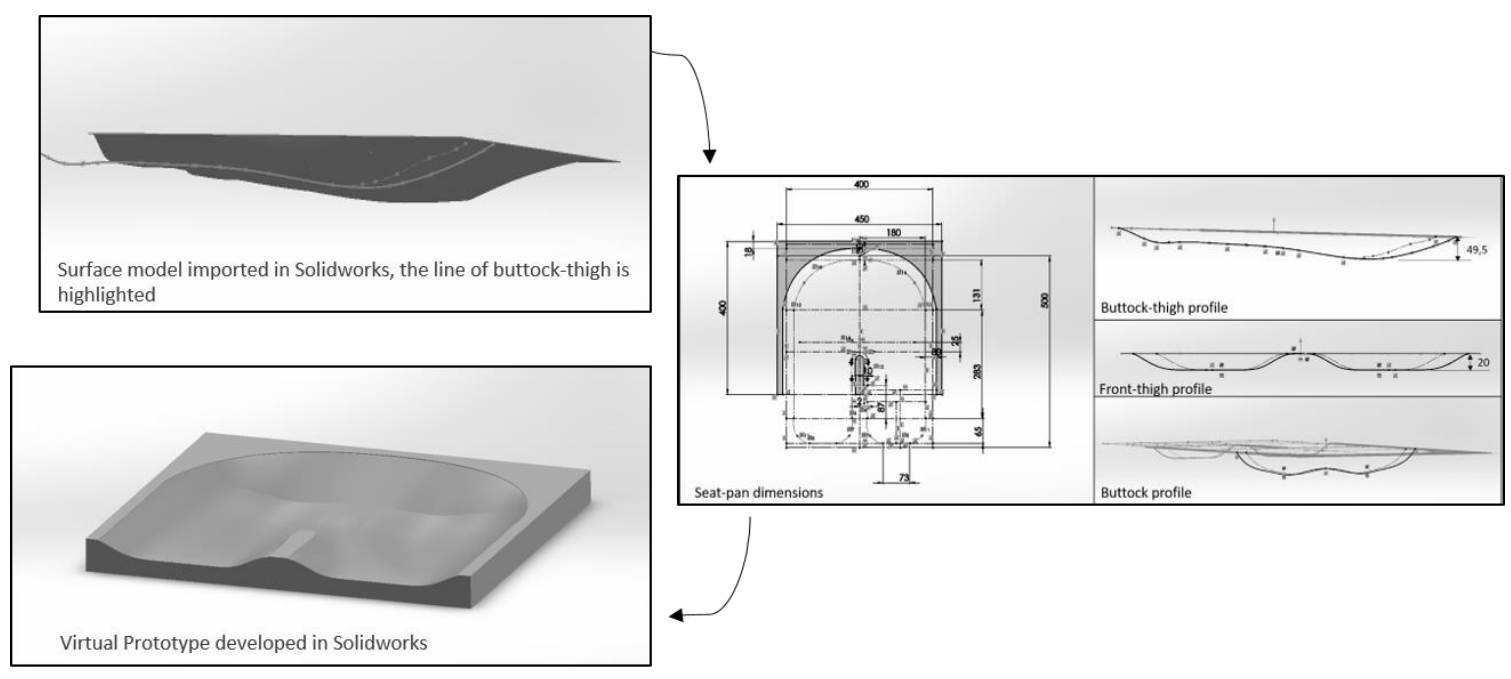

Figure 4: Phases of Virtual Prototype developing in Solidworks ${ }^{\circledR}$, starting from the imported surface, defining the shaped seat-pan cushion according to international population, and ending with the final Virtual Prototype

In the proposed virtual prototyping, authors combined Rhinoceros ${ }^{\circledR}$ and Solidworks $®$ in the process. Rhino is a NURBS-based 3-D modelling software with which the user can easily create and edit freeform surface. On the other side, SolidWorks ${ }^{\circledR}$ is a parametric and a feature-based CAD system, which allows users to edit the modelling at any time and go back on each time interval by feature design tree. Also, the user can enter the dimension to control the model shape and another related feature. Moreover, Solidworks ${ }^{\circledR}$ is more flexible in exporting or importing a Solid representation, e.g. it exports or imports about 25 CAD formats (Parasolid, IGES, step, STL, Rhino, AI, etc.). In contrast, Rhino has some limitation in exporting/importing Solid-bodies. Therefore, the choice had been made of utilizing the powerful NURBS surface modelling functions in Rhinoceros ${ }^{\circledR}$ (with Grasshopper®) and to use Solidworks ${ }^{\circledR}$ in the late stage for generating the desired output: a 3D model (Figure 4) in STL representation as the input of the CAM software of the CNC.

\subsection{Prototype}

The high-density polyurethane foam was selected as the prototyping materials and it was milling by a CNC machine with the shape of the seat-pan $(40 \times 37 \times 4 \mathrm{~cm})$. Later the edges were smoothed by a sanding machine. Then, it was covered by a layer of $2 \mathrm{~mm}$ thermoplastic sheet (Figure 5) via 
thermoforming to reinforce the mechanical properties of the seat pad (strong enough for approximately a 100kg load). Finally, a layer of a standard medium density polyurethane foam has been added on top, fixed with a cover. Authors did not apply glue between the foam and the thermoplastic cover of the seat pan for keeping the flexibility of the foam to follow the buttock shape for every participant. Another reason for not gluing was to hide the shape (Figure 5), in order not to influence participants' expectation (Naddeo et al., 2015).
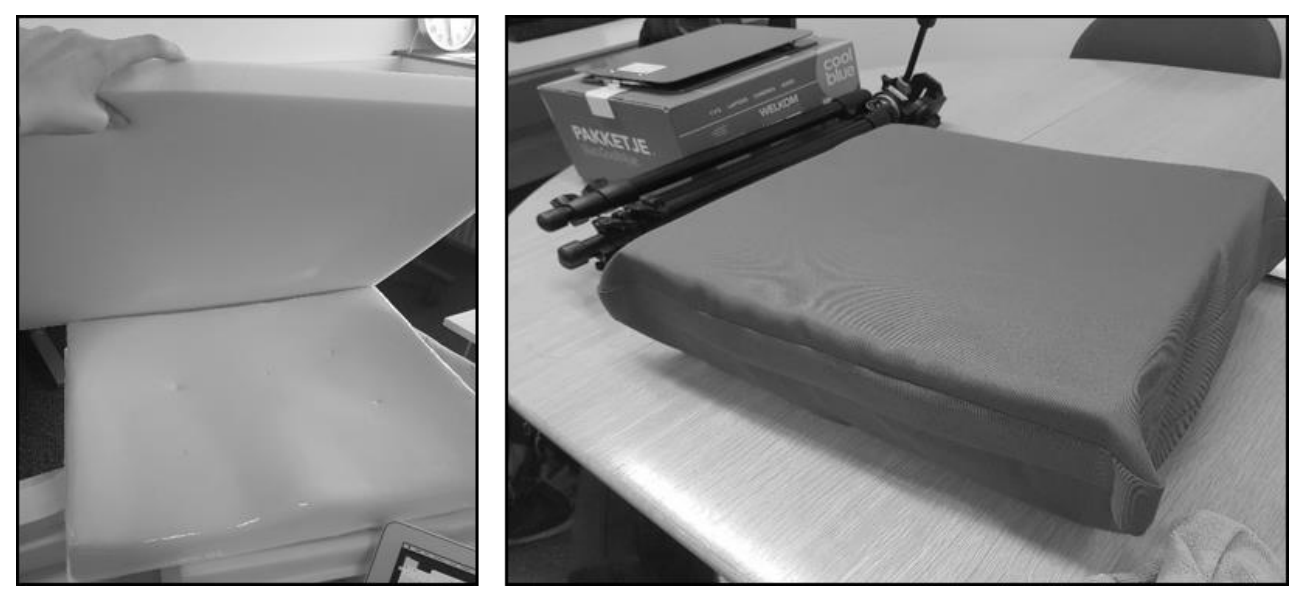

Figure 5: On the left: the prototype after thermoforming and adding the foam layer. On the right: the final model where the shape is hidden not to influence participants' expectations

\subsection{Validation of prototype: Experiment description}

This designed seat-pan has been used in experiments that compared perceived (dis)comfort, pressure distribution and contact area between the shaped seat-pan and the standard flat seat-pan. The experiment protocol has been approved by the Ethical Committee at the Delft University of Technology (TU Delft), in the Netherlands. The participants have been explained about the experiments and asked to complete the Informed Consent. Experiments lasted about 2 hours for each participant where they were asked to take 6 different postures for 7 minutes. Information about postural angles, pressure distribution and postural (dis)comfort have been gathered for each posture. Since the focus of this paper is to describe the methodology used to design the seat-pan and to examine results in terms of pressure distributions and contact areas, partial results of mentioned experiments are shown. The pressure mat has been placed on aircraft seats whose seat inclination was 4 degrees (as in current airplane seats aiming to represent the real condition) and the backrest inclination was 110 degrees.

\subsection{Validation of prototype: Participants}

Participants were recruited through the leaflets and social channels of TU Delft and by emails. The recruitment aimed to obtain a large sample of the international population in order to have high variability on age, height, weight, and body shape. A total number of 22 international participants (Chinese, Egyptian, Italian, Colombian, Mexican, Indonesian, Dutch), 11 males and 11 females, took part in experiments. This was the sample size needed to satisfy the statistical condition calculated with GPower software (Faul et al., 2007, 2009; Susanne et al., 2007). Anthropometric data are shown in Table 3.

Table 3: Anthropometric data of participants $(n=22)$

\begin{tabular}{c|ccccc} 
& Average & Median & Standard deviation & Max & Min \\
\hline Age & 28.73 & 27.50 & 5.55 & 48.00 & 24.00 \\
Weight $(\mathrm{kg})$ & 64.64 & 62.50 & 13.00 & 95.00 & 48.00 \\
Height $(\mathrm{cm})$ & 169.32 & 167.00 & 9.42 & 193.00 & 155.00 \\
BMI (Kg/m2) & 22.40 & 22.06 & 3.05 & 29.40 & 16.60 \\
WHR (waist-hip-ratio) & 0.84 & 0.84 & 0.06 & 0.96 & 0.72 \\
\hline
\end{tabular}




\subsection{Validation of prototype: Postures}

The planned postures were based on literature studies and are commonly assumed by passengers (Liu et al., 2019). However, the used aircraft seats had a fixed angle for the backrest, so the slouched/relaxed posture was hard to achieve and could not be studied. The order of the postures was planned using the Latin Square (Fisher, 1992) for experiment repeatability and reproducibility. The last posture was always the desired posture, where participants could assume their comfortable posture freely during a flight.

- Upright: The participant had to assume the upright posture, angle back-legs around $90^{\circ}$ and legs raised at $90^{\circ}$ at knee

- Elbow on legs: The participant was bended forward placing the elbows on the legs, and both thigh on the seat pan

- Legs crossed: The participant had to lay against the backrest and to have leg crossed, with the right leg on the left leg

- Arm on armrest: The participant should bend on the right side placing the arm on the armrest

- Legs crossed + arm on armrest: Crossing the legs (the left leg on the right leg), the participant should bend on the right side placing the arm on the armrest

- Preferred postures: The participant could perform any posture that he/she desired most

\subsection{Validation of prototype: Data from pressure mat}

The first analysis of the pressure mat data was the comparison between the two cushions in terms of pressure distribution and contact area. The pressure data gathering for each participant has been made three times for each posture obtaining 18 Excel files (6 postures x 3 files/posture) for each participant. Thus, there were 396 final files (18 files/participant x 22 participants) to analyse. For the first comparison, pressure distributions of each posture have been merged, obtaining an average pressure distribution and average contact area for each posture and participant. Then, the comparison between the two cushions has been made confronting the average pressures and contact areas. Table 1 shows the results of this comparison for each participant and each posture. Data from the shaped cushion have been subtracted with data from the flat one: negative values of average pressure mean the pressure distribution on the shaped cushion is lower than the flat cushion. Positive values of contact area mean the contact area on the shaped cushion is higher than the flat cushion. Finally, the mean values (Table 4) show the trends of the results, demonstrating that the shaped cushion presents less pressure and a larger contact area than the flat cushion.

Table 4: Result from the pressure mat: differences of average pressures and contact areas (desired values are negative values for pressure and positive values for contact area)

\begin{tabular}{|c|c|c|c|c|c|c|c|c|c|c|c|c|c|}
\hline \multicolumn{7}{|c|}{ Differences of Average Pressure N/cm2 (Shaped - Flat) } & \multicolumn{7}{|c|}{ Differences of Contact Area cm2 (Shaped - Flat) } \\
\hline $\begin{array}{c}\text { Particip } \\
\text { ant \# }\end{array}$ & $\begin{array}{c}\text { Uprig } \\
\mathrm{ht}\end{array}$ & $\begin{array}{l}\text { Elbows } \\
\text { on legs }\end{array}$ & $\begin{array}{c}\text { Leg } \\
\text { crossed }\end{array}$ & $\begin{array}{l}\text { Arm on } \\
\text { armrest }\end{array}$ & $\begin{array}{c}\text { Leg } \\
\text { crossed + } \\
\text { arm on } \\
\text { armrest }\end{array}$ & $\begin{array}{l}\text { Preferred } \\
\text { Posture }\end{array}$ & $\begin{array}{c}\text { Participant } \\
\#\end{array}$ & Upright & $\begin{array}{l}\text { Elbows } \\
\text { on legs }\end{array}$ & $\begin{array}{c}\text { Leg } \\
\text { crossed }\end{array}$ & $\begin{array}{l}\text { Arm on } \\
\text { armrest }\end{array}$ & \begin{tabular}{|c|} 
Leg \\
crossed + \\
arm on \\
armrest
\end{tabular} & $\begin{array}{c}\text { Preferred } \\
\text { Posture }\end{array}$ \\
\hline 1 & -0.05 & 0.00 & -0.07 & -0.04 & -0.06 & 0.06 & 1 & 345.70 & 80.11 & 179.57 & 175.27 & 99.67 & -20.97 \\
\hline 2 & -0.06 & -0.04 & -0.05 & -0.06 & -0.09 & -0.17 & 2 & -284.89 & 41.40 & 107.53 & 169.89 & 34.41 & 350.54 \\
\hline 3 & -0.07 & -0.02 & -0.02 & -0.06 & -0.04 & -0.07 & 3 & 537.87 & 43.77 & 106.45 & 59.68 & 80.64 & 60.75 \\
\hline 4 & -0.05 & 0.04 & -0.02 & -0.05 & -0.02 & 0.00 & 4 & 96.24 & 1.61 & 116.13 & 155.92 & 79.57 & 151.08 \\
\hline 5 & 0.00 & -0.02 & -0.05 & -0.02 & 0.04 & -0.03 & 5 & 217.74 & 135.48 & 157.53 & 178.50 & 90.86 & 67.74 \\
\hline 6 & 0.00 & 0.01 & -0.04 & -0.02 & -0.06 & 0.03 & 6 & 236.02 & 45.77 & 124.73 & 174.20 & 19.35 & 11.83 \\
\hline 7 & -0.05 & -0.06 & -0.09 & -0.04 & -0.05 & 0.07 & 7 & 155.91 & 15.05 & 54.84 & 98.39 & 103.23 & 25.81 \\
\hline 8 & -0.04 & -0.08 & -0.09 & -0.11 & -0.15 & -0.05 & 8 & 39.25 & 48.39 & 45.16 & -7.52 & 89.78 & 47.31 \\
\hline 9 & -0.01 & -0.05 & -0.01 & -0.09 & -0.04 & -0.09 & 9 & 29.57 & 30.64 & 66.67 & 70.43 & 77.42 & 16.67 \\
\hline 10 & -0.04 & -0.03 & -0.10 & -0.02 & -0.04 & -0.05 & 10 & 47.31 & 144.62 & 87.64 & 72.58 & 53.77 & 101.38 \\
\hline 11 & -0.01 & -0.04 & -0.04 & -0.09 & -0.08 & -0.08 & 11 & 262.37 & 229.03 & 164.52 & 88.17 & 66.13 & -19.35 \\
\hline 12 & -0.11 & -0.09 & -0.10 & -0.07 & -0.11 & -0.11 & 12 & 147.85 & 149.46 & 150.54 & 42.47 & 89.25 & 98.39 \\
\hline
\end{tabular}




\begin{tabular}{|c|c|c|c|c|c|c|c|c|c|c|c|c|c|}
\hline 13 & -0.03 & 0.00 & -0.01 & -0.03 & -0.05 & -0.02 & 13 & 195.70 & 34.41 & 49.46 & 124.73 & 121.51 & 128.49 \\
\hline 14 & -0.03 & -0.04 & 0.00 & 0.05 & 0.00 & -0.02 & 14 & 5.38 & -33.87 & -51.61 & 69.35 & 44.63 & 41.94 \\
\hline 15 & -0.11 & 0.04 & 0.00 & 0.00 & -0.02 & 0.06 & 15 & 322.69 & 136.56 & 143.55 & 153.23 & 13.98 & 37.10 \\
\hline 16 & -0.01 & 0.00 & -0.06 & -0.01 & -0.12 & -0.07 & 16 & 146.77 & 163.44 & 195.70 & 146.24 & 347.31 & 213.98 \\
\hline 17 & 0.00 & -0.02 & -0.10 & -0.03 & -0.04 & -0.01 & 17 & 145.63 & 56.99 & 154.30 & 151.07 & 120.43 & 93.55 \\
\hline 18 & 0.02 & 0.05 & -0.01 & -0.01 & -0.02 & 0.01 & 18 & 121.51 & -100.54 & 205.92 & 137.10 & 95.16 & 103.76 \\
\hline 19 & 0.04 & 0.02 & 0.12 & 0.02 & -0.03 & 0.03 & 19 & 68.28 & 31.72 & 85.48 & -90.33 & 42.47 & 193.01 \\
\hline 20 & -0.12 & -0.07 & 0.00 & -0.08 & -0.06 & -0.26 & 20 & 100.00 & 27.42 & 13.44 & 41.93 & 23.12 & 623.12 \\
\hline 21 & 0.03 & 0.07 & 0.05 & -0.03 & 0.03 & 0.00 & 21 & 138.18 & 46.77 & 44.09 & 16.67 & 50.00 & -41.94 \\
\hline 22 & -0.02 & 0.03 & -0.06 & -0.02 & -0.01 & -0.18 & 22 & 83.87 & 67.74 & 155.37 & 216.67 & 60.75 & 266.66 \\
\hline MEAN & $-0,03$ & $-0,01$ & $-0,03$ & $-0,04$ & $-0,05$ & $-0,04$ & MEAN & 143,59 & 63,45 & 107,14 & 102,03 & 81,97 & 115,95 \\
\hline
\end{tabular}

\section{RESULTS AND DISCUSSION}

Planned comparisons (Table 2) revealed that, the difference in average pressure between shaped cushion and flat cushion is always negative, meaning that the shaped cushion is having lower pressure values. Consequently, the shaped cushion could follow the human contour better than the flat cushion. The contact area is also mostly larger for the shaped cushion, meaning that there is more contact between the cushion and the human body, distributing the weight of the human over a larger area. This is preferable as there ere are indications that a seat contour resulting in a large contact area is correlated to more comfort (Fang et al., 2016; Zemp et al., 2015).

\section{CONCLUSION}

A shaped seat pan has been designed aiming to have a contour that follows the buttock-thigh contour of an international population. To study the effect of this shaped cushion, a comparison has been made with a flat cushion. Geometric data have been processed in Grasshopper (within the Rhino software) for a freeform surface which follows the shape of the buttock. Based on this freeform surface, a solid model of the seat-pan was created in SolidWorks. Then, the shape has been manufactured with the $\mathrm{CNC}$ machine on high-density foam. Then, the prototype was later smoothed and reinforced by a layer of thermoplastic using thermoforming. Finally, a standard foam layer (with standard density, as the flat cushion) was added on the top of the seat-pan. Experiment results showed that the main goal had been reached, i.e. using the shaped seat pan, the average pressure is lower, and the contact area is larger than using the flat seat-pan. This is aligned with literature studies (Fang et al., 2016; Kamp, 2012; Zemp et al., 2016; Zenk et al., 2012). Besides, the proposed prototyping approach (Gibson et al., 2004; Liu, 2011) also highlights the possibility of realizing a modifiable and reproducible design (Virtual Prototype) and then a Physical Prototype in a short time and with few iterations. This design approach, easily reproducible and adaptable for every type of chair or seat-pan, was based on the simultaneous use of three standard methods: 1) the analysis of pressures (Hiemstra-van Mastrigt, Groenesteijn, et al., 2016; De Looze et al., 2003; Wang et al., 2020; Zemp et al., 2015) and contact areas (Fang et al., 2016; Zemp et al., 2016; Zenk et al., 2012); 2) the analysis of different fixed postures (Groenesteijn et al., 2014; Hiemstra-van Mastrigt, Groenesteijn, et al., 2016, Naddeo et al., 2018); 3) the analysis of perceived discomfort through questionnaires (El Falou et al., 2003; Kyung and Nussbaum, 2008; Mansfield et al., 2015; Naddeo et al., 2019; Naddeo and Memoli, 2009; Zenk et al., 2006). The originality, therefore, lies in the triple evaluation and in the project proposal. However, some limitations need to be acknowledged: even though the sample was statistically significant according to the GPower calculator, experiments could be executed with a higher number of people so managing a more significant sample to increase accuracy; also, the choice of the material, in particular the foam, could have influenced results. As future development, the experiment should be replicated comparing several types of foam. Also, further test with different contours could be useful to understand better the impacts of materials and different contour selected. 


\section{REFERENCES}

A consensus document. (2010), "International review. Pressure ulcer prevention: pressure, shear, friction and microclimate in context.", Wounds International.

Anderl, R., Mecke, K. and Klug, L. (2007), “Advanced Prototyping With Parametric Prototypes”, pp. 503-510.

Cascioli, V., Liu, Z., Heusch, A. and McCarthy, P. (2016), “A methodology using in-chair movements as an objective measure of discomfort for the purpose of statistically distinguishing between similar seat surfaces", Applied Ergonomics, Vol. 54, pp. 100-109.

“DINED". (n.d.), available at: https://dined.io.tudelft.nl/en/database/tool.

El Falou, W., Duchêne, J., Grabisch, M., Hewson, D., Langeron, Y. and Lino, F. (2003), "Evaluation of driver discomfort during long-duration car driving”, Applied Ergonomics, Elsevier, Vol. 34 No. 3, pp. $249-255$.

Fang, F., Shen, L., Chen, Y. and Yuding, Z. (2016), "A Method for Measuring the Weight of Body Segment Based on Human Model and Body Pressure Distribution", Vol. 485, pp. 735-741.

Faul, F., Erdfelder, E., Buchner, A. and Lang, A.-G. (2009), "Statistical power analyses using G*Power 3.1: Tests for correlation and regression analyses", Behavior Research Methods, Vol. 41 No. 4, pp. 1149-1160.

Faul, F., Erdfelder, E., Lang, A.-G. and Buchner, A. (2007), "G*Power 3: A flexible statistical power analysis program for the social, behavioral, and biomedical sciences”, Behavior Research Methods, Vol. 39 No. 2, pp. 175-191.

Fisher, R.A. (1992), "Statistical Methods for Research Workers”, in Kotz, S. and Johnson, N.L. (Eds.), Breakthroughs in Statistics: Methodology and Distribution, Springer New York, New York, NY, pp. 66-70.

Franz, M., Zenk, R., Durt, A. and Vink, P. (2008), "The Influence of a Massage Car Seat on Comfort Experience and EMG", available at:https://doi.org/10.4271/2008-01-0889.

Gibson, I., Gao, Z. and Campbell, R.I. (2004), “A comparative study of virtual prototyping and physical prototyping”, IJMTM, Vol. 6, pp. 503-522.

Groenesteijn, L., Hiemstra-van Mastrigt, S., Gallais, C., Blok, M., Kuijt-Evers, L. and Vink, P. (2014), "Activities, postures and comfort perception of train passengers as input for train seat design", Ergonomics, Vol. 57, pp. 1-12.

Hartung, J., Mergl, C. and Bubb, H. (2004), "Reliability of Pressure Measurement on Car Seats”, SAE Technical Papers, Vol. 113, available at:https://doi.org/10.4271/2004-01-2167.

Helander, M. and Zhang, L. (1997), "Field studies of comfort and discomfort in sitting”, Ergonomics, Vol. 40, pp. 895-915.

Hiemstra-van Mastrigt, S., Groenesteijn, L., Vink, P. and Kuijt-Evers, L. (2016), "Predicting passenger seat comfort and discomfort on the basis of human, context and seat characteristics: a literature review", Ergonomics, Vol. 60, pp. 1-44.

Hiemstra-van Mastrigt, S., Meyenborg, I. and Hoogenhout, M. (2016), "The influence of activities and duration on comfort and discomfort development in time of aircraft passengers", Work, Vol. 54, pp. 1-7.

Kamp, I. (2012), "The influence of car-seat design on its character experience", Applied Ergonomics, Elsevier, Vol. 43 No. 2, pp. 329-335.

Kolich, M. and Taboun, S.M. (2004), "Ergonomics modelling and evaluation of automobile seat comfort", Ergonomics, Taylor \& Francis, Vol. 47 No. 8, pp. 841-863.

Krouskop, T.A., Noble, P.C., Garber, S.L. and Spencer, W.A. (1983), “The effectiveness of preventive management in reducing the occurrence of pressure sores.", Journal of Rehabilitation R\&D, United States, Vol. 20 No. 1, pp. 74-83.

Kyung, G. and Nussbaum, M. (2008), "Driver sitting comfort and discomfort (Part II): Relationships with and prediction from interface pressure", International Journal of Industrial Ergonomics, Vol. 38, pp. 526-538.

Liu, B. (2011), Design School Integration Of Physical And Virtual Prototyping, Loughborough University.

Liu, J., Yu, S. and Chu, J. (2019), “The Passengers' Comfort Improvement by Sitting Activity and Posture Analysis in Civil Aircraft Cabin”, edited by Renno, F.Mathematical Problems in Engineering, Hindawi, Vol. 2019, p. 3278215.

De Looze, M.P., Kuijt-Evers, L.F.M. and Van Dieen, J. (2003), "Sitting comfort and discomfort and the relationships with objective measures", Ergonomics, Taylor \& Francis, Vol. 46 No. 10, pp. 985-997.

Mansfield, N., Sammonds, G. and Nguyen, L. (2015), "Driver discomfort in vehicle seats - Effect of changing road conditions and seat foam composition", Applied Ergonomics, Elsevier, Vol. 50, pp. 153-159.

McManus, A.M., Ainslie, P.N., Green, D.J., Simair, R.G., Smith, K. and Lewis, N. (2015), "Impact of prolonged sitting on vascular function in young girls", Experimental Physiology, Vol. 100 No. 11, pp. 1379-1387.

Molenbroek, J.F.M., Albin, T.J. and Vink, P. (2017), "Thirty years of anthropometric changes relevant to the width and depth of transportation seating spaces, present and future”, Applied Ergonomics, Vol. 65, pp. 130-138.

Naddeo, A., Di Brigida, L., Fontana, C., Montese, J., Quartuccia, M., Nasti, M., Pisani, M.M., et al. (2019), “A body-shaped lumbar-sacral support for improving car-seat comfort”, Work. 
Naddeo, A., Califano, R. and Vink, P. (2018), “The effect of posture, pressure and load distribution on (dis)comfort perceived by students seated on school chairs", International Journal on Interactive Design and Manufacturing, available at:https://doi.org/10.1007/s12008-018-0479-3.

Naddeo, A., Cappetti, N., Califano, R. and Vallone, M. (2015), "The Role of Expectation in Comfort Perception: The Mattresses’ Evaluation Experience”, Procedia Manufacturing, Vol. 3, available at: https://doi.org/10.1016/j.promfg.2015.07.582.

Naddeo, A. and Memoli, S. (2009), Postural Comfort inside a Car: Development of an Innovative Model to Evaluate the Discomfort Level, SAE International Journal of Passenger Cars -Mechanical Systems, Vol. 2.

Schubert, V., Perbeck, L. and Schubert, P.-Å. (1994), "Skin microcirculatory and thermal changes in elderly subjects with early stage of pressure sores", Clinical Physiology, Vol. 14 No. 1, pp. 1-13.

Smulders, M., Berghman, K., Koenraads, M., Kane, J.A., Krishna, K., Carter, T. and Schultheis, U. (2016), "Comfort and pressure distribution in a human contour shaped aircraft seat (developed with 3D scans of the human body)", Work, Vol. 54, pp. 1-16.

Stephens, M. and Bartley, C. (2017), "Understanding the association between pressure ulcers and sitting in adults what does it mean for me and my carers? Seating guidelines for people, carers and health \& social care professionals", Journal of Tissue Viability, Vol. 27, available at:https://doi.org/10.1016/j.jtv.2017.09.004.

Susanne, M., Erdfelder, E., Buchner, A. and Faul, F. (2007), "A short tutorial of GPower”, Tutorials in Quantitative Methods for Psychology, Vol. 3, available at:https://doi.org/10.20982/tqmp.03.2.p051.

Thosar, S., Bielko, S., Mather, K., Johnston, J. and Wallace, J. (2014), "Effect of Prolonged Sitting and Breaks in Sitting Time on Endothelial Function", Medicine and Science in Sports and Exercise, Vol. 47, available at:https://doi.org/10.1249/MSS.0000000000000479.

Vink, P. (2016), Vehicle Seat Comfort and Design, 1st ed.

Vink, P. and Lips, D. (2017), "Sensitivity of the human back and buttocks: The missing link in comfort seat design", Applied Ergonomics, Vol. 58, pp. 287-292.

Wang, X., Savonnet, L., Beurier, G. and Obadia, J. (2020), “An Experimental Investigation of Preferred Seat Pressure Distribution", pp. 330-335.

Zemp, R., Taylor, W. and Lorenzetti, S. (2015), "Are pressure measurements effective in the assessment of office chair comfort/discomfort? A review”, Applied Ergonomics, Vol. 48, available at:https://doi.org/10.1016/j.apergo.2014.12.010.

Zemp, R., Taylor, W.R. and Lorenzetti, S. (2016), "Seat pan and backrest pressure distribution while sitting in office chairs.”, Applied Ergonomics, England, Vol. 53 Pt A, pp. 1-9.

Zenk, R., Franz, M., Bubb, H. and Vink, P. (2012), “Technical note: Spine loading in automotive seating”, Applied Ergonomics, Vol. 43 No. 2, pp. 290-295.

Zenk, R., Mergl, C., Hartung, J., Sabbah, O. and Bubb, H. (2006), “Objectifying the Comfort of Car Seats”, SAE 2006 World Congress \& Exhibition, SAE International, available at:https://doi.org/https://doi.org/10.4271/2006-01-1299.

Zhang, L., Helander, M.G. and Drury, C.G. (1996), "Identifying Factors of Comfort and Discomfort in Sitting", Human Factors, Vol. 38 No. 3, pp. 377-389. 